Conference Article

\title{
Modeling Cavitation in ICE Pistons Made with Isothermal Forging
}

\author{
V.V. Astanin*, A.A. Shakhovkina, F.F. Safin, M.O. Melnikov, A.M. Yamileva and A.T. Bikmeyev
}

Ufa State Aviation Technical University, Ufa, Russian Federation

Received 15 September 2014; Accepted 20 September 2014

\begin{abstract}
Possible causes for cavitations in parts made with an Al-Si eutectic alloy AK12D (AlSi12) were explored with mathematical and physical modeling with involved acoustic emission. Pores were formed from micro-cracks, which appear during the early stages of a deformation process, with the help of micro-stresses appearing at phase boundaries (A1/Si interface) due to thermal expansion. At the design stage of isothermal forgings of such products it is recommended to provide a scheme of the deformed shape, which is under uniform compression, to compensate for the inter-phase stresses.
\end{abstract}

Keywords: ICE, isothermal forging, cavitation, ANSYS.

\section{Introduction}

The main objective behind this research was the existence of considerable porosity, $15 \%$ of the bulk volume, which was found in the bulk of a piston of a light aviation engine before the end of life-cycle. The development of such porosity can lead to the catastrophic destruction of the piston. But a fully reliable part can be produced during manufacturing, if the nature of cavitations and its dynamics can be understood and therefore controlled. For pistons manufacture heat-resistant aluminum alloys with Al-Si-Cu-Mg eutectic and hypereutectic compositions are used [1]. Despite the large number of diverse studies on the alloys of this group [2-5], the causes of porosity and fracture are not fully understood. The purpose of the research is to determine the causes and the dynamics of pore formation in the piston alloy using mathematical and physical modeling. For this purpose the method of acoustic emission (AE) was used, which enhances information on the process of plastic deformation and destruction of material during testing. [6].

\section{Experiments}

All experiments were made with AK12D (AlSi12) alloy with a chemical composition $\mathrm{Al}-11,25 \mathrm{Si}-0,35 \mathrm{Fe}-1,89 \mathrm{Cu}$ - 0,39Mn - 0,91Mg - 0,02Cr - 0,99Ni - 0,32Zn - 0,079Ti (in mass \%) and average size of particles of $5 \mu \mathrm{m}$. The structure of the piston and of the alloy samples were studied before and after tests with optical microscopy (OLYMPUS GX 51) and with scanning electron microscopy (JSM-6390). Samples did undergo uniaxial tension at $380^{\circ} \mathrm{C}$ in a tensile testing machine INSTRON 8862 at a crosshead speed of 1

\footnotetext{
*E-mail address: vvastanin@yandex.ru

ISSN: 1791-2377 (C) 2014 Kavala Institute of Technology. All rights reserved.
}

$\mathrm{mm} / \mathrm{min}$. The temperature of $380^{\circ} \mathrm{C}$ was chosen because it is the maximum operating temperature of the piston.

AE signals were recorded using a "Malachite AC-12A" and a resonant type converter DR15I. The intrinsic noise of the machine and equipment did not exceed the threshold of sensitivity of $25 \mathrm{~dB}$. The transducer was mounted on a special clamp fixed to the upper rod of the machine, which also served as a waveguide. AE signals were analyzed according to amplitude, energy, duration and frequency of events. The AE signals were synchronized to the stressstrain diagram of each individual sample, to identify each stage of stretching microcracks.

Mathematical modeling of forging was made in DEFORM 3D software. Isothermal conditions of forging were used, coefficient of friction was set to 0.25 , temperature was $450^{\circ} \mathrm{C}$, speed of the tool was $1 \mathrm{~mm} / \mathrm{s}$. The joint thermal expansion of the aluminum matrix and silicon particles under heating from $20^{\circ} \mathrm{C}$ to $300^{\circ} \mathrm{C}$ was modeled

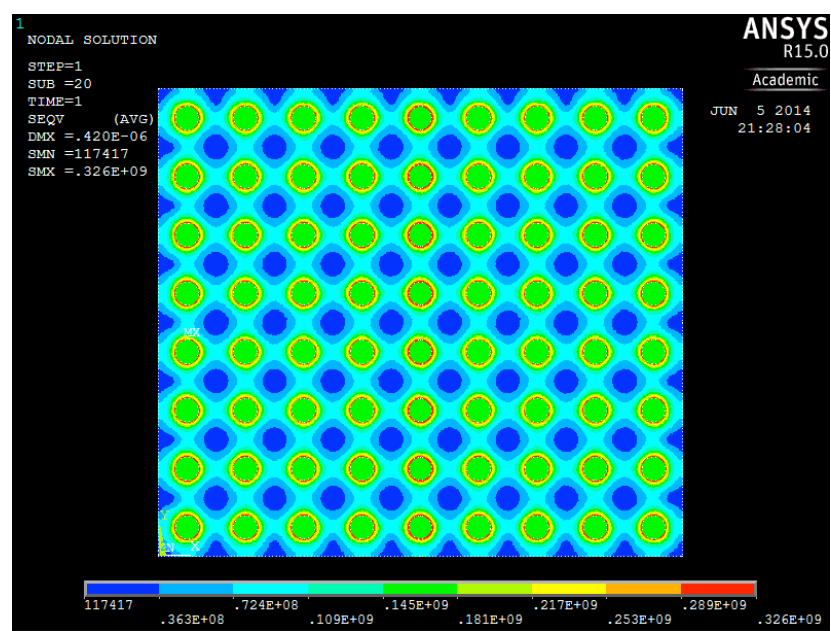

Fig. 1. Von Misses stress field 
with ANSYS R15. The coefficients of thermal expansion and Young modulus were : $\alpha_{\mathrm{Al}}=22,2 \cdot 10-6{ }^{\circ} \mathrm{C}^{-1}$ and $\alpha_{\mathrm{Si}}=5,1 \cdot 10^{-6} ; \quad E_{\mathrm{Al}}=70 \mathrm{GPa}$ and $E_{\mathrm{Si}}=109 \mathrm{GPa}$, and corresponding values of density and Poisson coefficient were used also. The main objective of the analyses was the calculation of the stress field on the Al-Si boundaries of particles. Modeling was made as a 2D static problem (see Fig.1) with a square periodic arrangement of 72 particles. The particles had form of circle and square with a size of 5 microns, so as to occupy $12.6 \%$ and $16 \%$ of full area, similar to the real case. Heat propagation was not taken into account.

\section{Results and Discussion}

The porosity in the structure of the used piston can be seen in Fig.2, that was made from the Al alloy AK12D with isothermal forging. The porosity is not characteristic neither of the material nor the forgings. Most pores were found in the interface between particles and matrix. This is not surprising when taken into account the significant difference of the coefficients of thermal expansion and elastic modulus of silicon, intermetallics and aluminum matrix. It should be pointed out that into the guiding part of the piston skirt porosity is significantly higher (about 15\%) than in the annular grooves of the piston area (about 5\%).

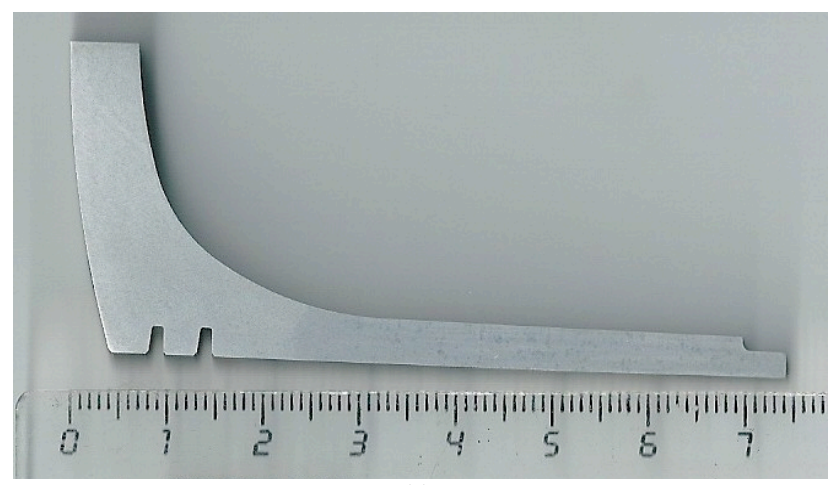

(a)

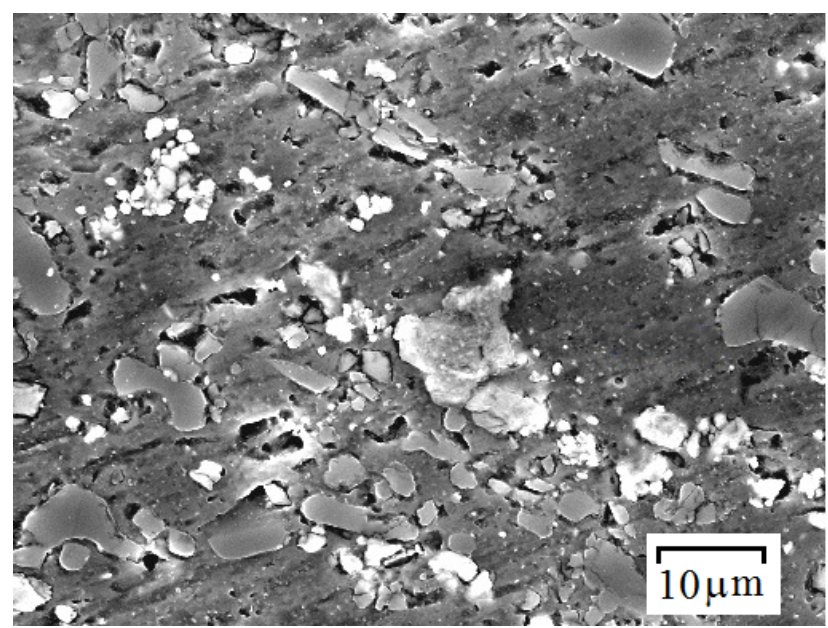

(b)

Fig.2. Photograph of the piston (a) and a microstructure of the piston skirt (SEM) (b)

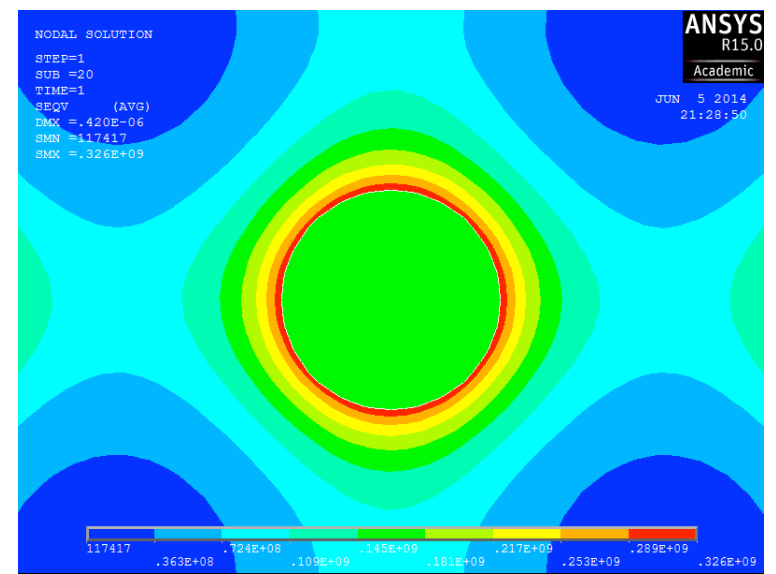

(a)

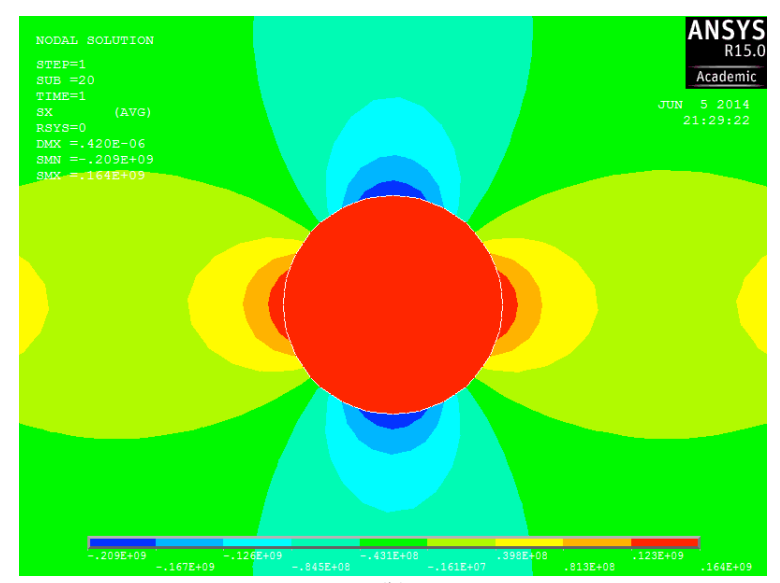

(b)

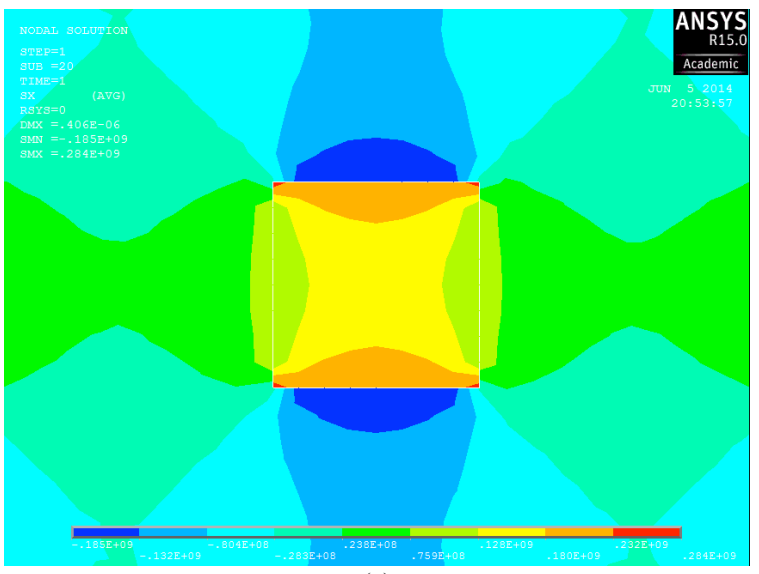

(c)

Fig. 3. Stress fields that develop due thermal expansion in the system Al-Si. (a) Von Misses stress field for circle shape particles, (b) stress along X-axis for circle shape particles, (c) Von Misses stress field for square shape particles.

The shape, size and arrangement of the pores let one suppose, that they are formed from microcracks on the interfaces between particles and matrix. Initial cracks are either inherited from forging or appear as a result of the thermal expansion during heating.

The simulation of the joint thermal expansion of phases during heating when taking into account the effect of neighboring particles had showed (see Fig.3a), that the highest von Misses stresses were concentrated near the interface of Al-Si and reached a value of $320 \mathrm{MPa}$. The 
deformed shape that the analysis of stresses along a primary axis, is shown, for example for $\sigma_{x}$ in (Fig. 3,b). Due to the difference between thermal and elastic constants of different phases, tensile stresses arise near the particle's surface during thermal expansion, reaching $160 \mathrm{MPa}$. On the flat faces of particles (see Fig.3,c) the distribution of stresses is more uniform reaching $128 \mathrm{MPa}$. At high temperatures, this level of stresses is enough to produce local deformations and detachment of particles from the matrix. Nevertheless, when studied there is not mass separation of particles during sample heating, with only limited cases appearing.

This situation can change when external pressure is applied as a result of external and thermal stresses applied together. The case was studied with uniaxial tensile testing of $\mathrm{AK} 12 \mathrm{D}$ at $380^{\circ} \mathrm{C}$.

The tensile testing chart of the sample and diagram of AE signals are shown in Figure $4 \mathrm{a}$ and $4 \mathrm{~b}$ respectively. Each point corresponds to a separate event, which takes place at some time and is characterized by the amplitude of the signal. It can be seen, that acoustic activity takes place from the initial stage of deformation before yield stress. The maximum value of the amplitude of signals and of event's frequency corresponds to the maximum of deformation stresses. When plastic flow begins, acoustic activity decreases rapidly. The following peaks of activity appear at $6-8 \%$ deformation and closer to the sample fracture.

Acoustic activity indicates that microcracks have appeared. They are hard to detect in a structure, but as the sample deformed microcracks are stretched and convert to pores, which can be clearly identified (see Fig 4,b). Most of the pores originate at the interface between particles and matrix, which are normal to the axis of tension. The opening of microcracks in highly stressed areas facilitates the flow of the material, reducing deformation stresses and acoustic activity.

Thus, the sum of internal and external stresses can lead to cavitation, and initial microcracks on the interface between particles and matrix can appear during production of a piston.

It should be stated that most pores are detected at the "skirt" of the piston, where most intensive material flow takes place during forging. It is possible to affect initial crack formation by changing the stress-strain mode with another design of the die.

There are drafts on the inner and outer surfaces of the forged piece for easy retrieve from the die. These drafts are shown as vertical bias angles $\varphi_{1}$ and $\varphi_{2}$ on Fig 5,a. Modeling of the deformation conditions for different sets of these angles was performed. The angle $\varphi_{1}$ was constant at $1^{\circ} 30^{\prime}$, and two values were used for $\varphi_{2}$ at $\varphi_{2}=1^{\circ} 30^{\prime}$ and $\varphi_{2}=0^{\circ} 30^{\prime}$. Results of the analyses were estimated in terms of material damage, using the expression of Cockroft and Latem:

$$
D=\int \frac{\sigma^{*}}{\bar{\sigma}} d \bar{\varepsilon}
$$

where $\sigma^{*}, \bar{\sigma}$ and $d \bar{\varepsilon}$ are maxima of tensile stresses, stress intensity; and an increment of strain intensity. An example of damage distribution is shown in Fig.5, b.

It can be seen, that the minimum damage appears at the bottom of the piston, and increases further away from the bottom

There are points in Fig.5, $\mathrm{b}$ for which values of damage at different combination of angles values were calculated and shown in Fig.6. Curve 1 corresponds to a bias $\varphi_{2}=1^{\circ} 30^{\prime}$, and curve 2 corresponds to $\varphi_{2}=0^{\circ} 30^{\prime}$. This comparison shows that decreasing of angle $\varphi_{2}$ value leads to significant decrease of damage. In essence, a reduction in tensile stress suppresses cavitation.

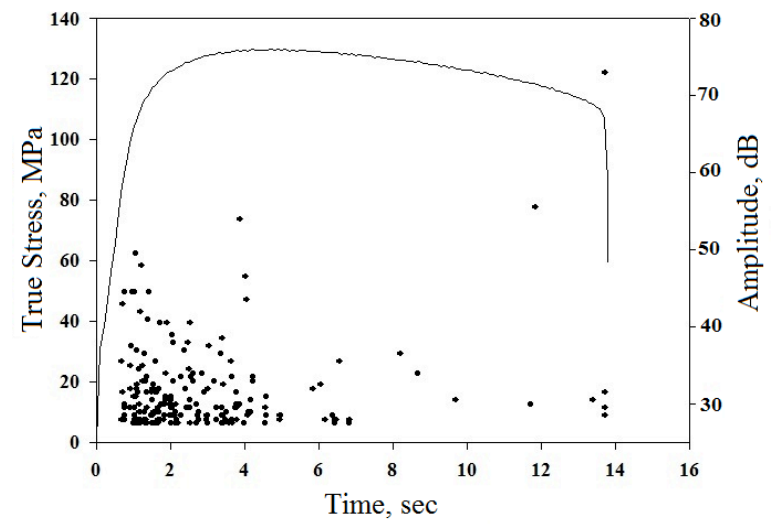

(a)

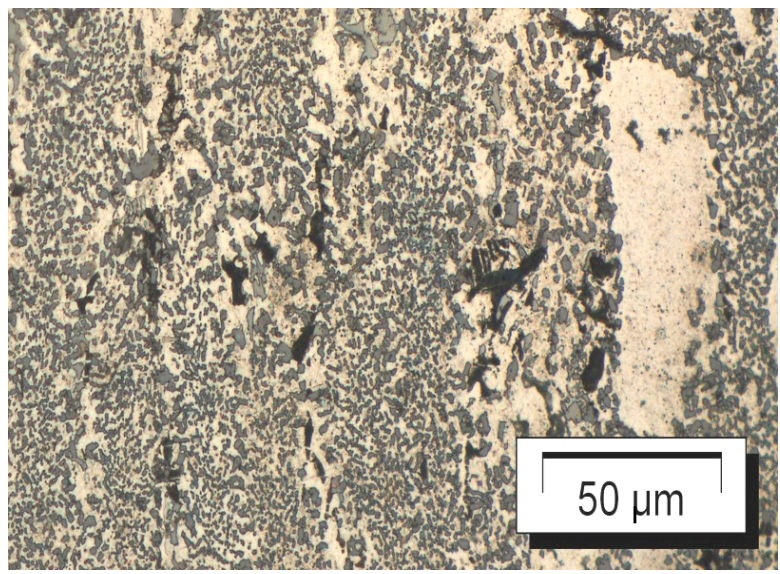

(b)

Fig.4. Tensile strength and diagram of AE signals at $380{ }^{\circ} \mathrm{C}$ temperature (a); microstructure of the stretched sample (b).

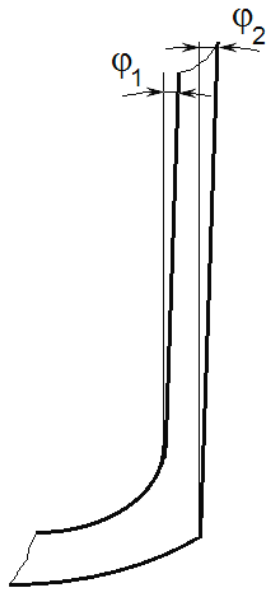

(a)

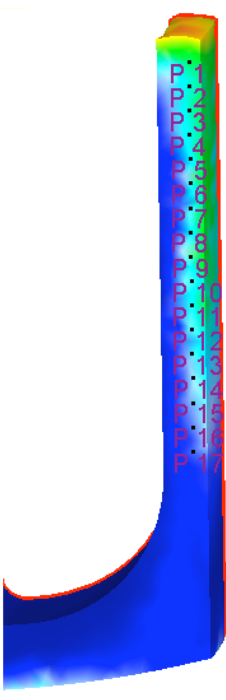

(b)

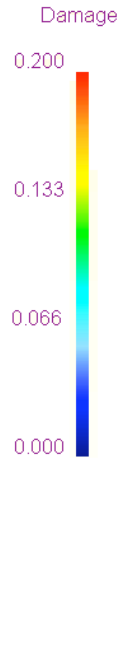


Fig. 5. Cross-section of a section of the piston (a) and distribution of damage in this part (b)

The damage values themselves are not as large as to cause microcracks, but when combined with stresses at the interface of $\mathrm{Al}-\mathrm{Si}$, caused by thermal expansion, then they may have a negative effect.

Thus, it is possible to compensate for tensile stresses on the interface between the particles and the matrix and to reduce the likelihood of pore formation by creating a narrowing channel for the flow of material into the die.

\section{Conclusions}

The tendency to cavitate, when the AK12D alloy is used in a piston, is caused during isothermal forgings which result in microcracks in the bulk. Local stresses on the interface between particles and matrix contribute to the formation of microcracks, due to the difference in their thermal expansion coefficients. To compensate for the tensile stresses at the interface and to reduce the likelihood to form microcracks during isothermal forging it is possible to create state of stress-strain which includes components of uniform compression.

\section{Acknowledgment}

This work was produced during the joint project between USATU (Ufa State Aviation Technical University) and UMPO (Ufa Engine Industrial Association) with title "Elaboration and industrial development of high-precision shaping coordinated technologies and superficial hardening of responsible details from Al-alloys with heightened constructional energy efficiency", implemented under the contract №40/10-30976 sponsored by the Ministry of Education and Science of the Russian Federation (contract №02.G25.31.0010 between UMPO and the Ministry of Education and Science of the Russian Federation) through the Resolution of the Russian Federation Government № 218 from April 9, 2010.

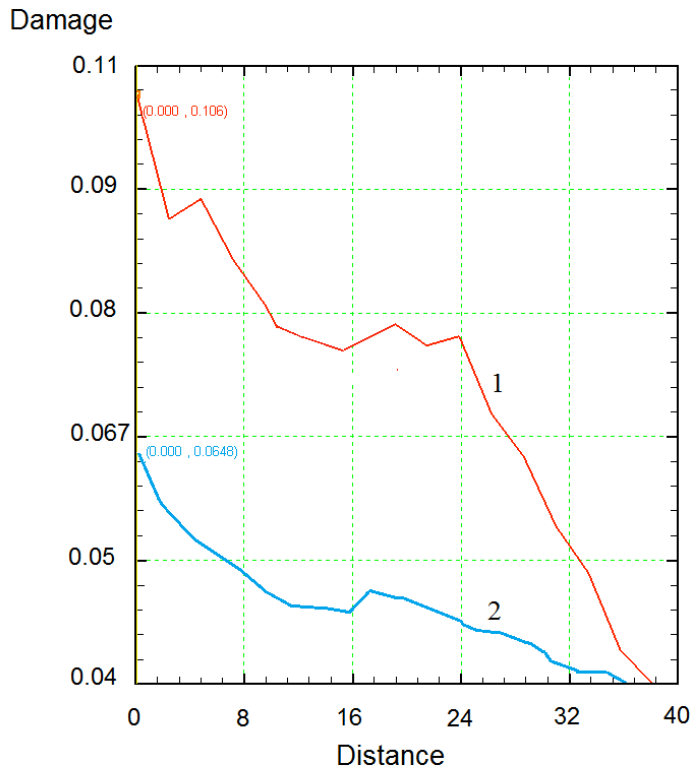

Fig. 6. Dependence of material's damage on distance of point P1 till next points (fig. 5 , b).

\section{References}

[1] D. F. Tariq, N. Naz, R.A. Baloch, Faisal Characterization of Material Properties of 2xxx Series Al-Alloys by Non Destructive Testing Techniques/ J Nondestruct Eval (2012) 31:17-33

[2] Hao Wang, Changsheng Li, Jing Li, Xinglong Wei, and Ruibin Mei Effect of Deformation and Aging on Properties of Al- $4.1 \% \mathrm{Cu}$ $1.4 \% \mathrm{Mg}$ Aluminum Alloy / ISRN Materials Science Volume 2013, Article ID 902970, 8 pages

[3] Berger, H.: Nondestructive characterization of materials. Mater. Eval. 50, 299-305 (1992)

[4] Rosen, M., Horowits, E., Swartzendruber, L., Fick, S., Mehrabian,R.: The aging process in aluminum alloy 2024 studied bymeans of eddy currents. Mater. Sci. Eng. 53(2), 191-198 (1982)

[5] Tiryakioglu, M., Campbell, J., Staley, J.T.: Hardness-strength relationships in cast $\mathrm{Al}-\mathrm{Si}-\mathrm{Mg}$ alloys. Mater. Sci. Forum 331337,295-300 (2000).

[6] S.V. Panin, O.V. Bashkov, N.A. Semashenko, V.E. Panin, S.V. Zolotareva Combined study of deformation features of flat and notched samples at the micro and the meso levels by methods of acoustic emission and mapping of surface deformations. // Phys.Mesomech, vol.7, spec.issue 2, 2004. p.303-306. (In Russian) 